\title{
A surgical approach in the treatment of preputial gland abscesses in mice
}

\author{
Henri G. M. J. Bertrand ${ }^{1 *}$, Aurelie A. Thomas ${ }^{1}$, Yvette C. Ellen ${ }^{1,2}$, Robert S. Dorward ${ }^{2}$ and Paul A. Flecknell ${ }^{1,3}$
}

\begin{abstract}
Background: Preputial gland infection is a common occurrence in non-breeder male mice and can lead to abscesses. This report describes a surgical approach to treating and preventing this condition.

Results: Surgical removal of the glands was undertaken in 258 male $\mathrm{C} 3 \mathrm{H} / \mathrm{HeNH}$ sd mice. The glands were successfully removed in all of the animals with a low rate of post-surgery complications. Abscess recurrence due to incomplete gland resection occurred in $2.3 \%$ of animals. Surgical wound opening (3.1\%) and infection of the surgical site (2.3\%) also occurred but were treated successfully.
\end{abstract}

Conclusion: In the study described here, early intervention was successful in preventing intercurrent infection compromising both animal welfare and the outcome of the study.

Keywords: Refinement, Preputial, Gland, Surgery, Abscess

\section{Background}

Preputial glands are accessory glands of the reproductive system of the male mouse and play a role in reproduction and dominance behavior $[1,2]$. Inflammation and infection of these glands can lead to abscess formation. This health issue occurs more frequently in some mouse strains such as $\mathrm{B} 6 \mathrm{C} 3 \mathrm{~F} 1[3,4]$ however the incidence is usually quite low in $\mathrm{C} 3 \mathrm{H}$ mice $[5,6]$. The usual presentation of preputial gland inflammation is a uni- or bilateral subcutaneous swelling on either side of the prepuce. This develops to form a palpably hard mass and the overlying skin can be inflamed. In the worst case the abscesses can ulcerate and purulent exudate can be visible on the coat (Fig. 1). During a long-term (12 month) study in our facility, a high incidence of abscesses were noted, and the principal investigator was concerned at the impact of chronic infection and antibiotic treatment on both mouse welfare and the scientific goals of the study. To try to resolve the problem, a procedure to remove the glands surgically was developed, and this was used both to treat established abscesses, and as a preventive measure.

\footnotetext{
* Correspondence: henri.bertrand@ncl.ac.uk

${ }^{1}$ Comparative Biology Centre, Newcastle University, Framlington Place, Newcastle Upon Tyne NE2 4HH, UK

Full list of author information is available at the end of the article
}

\section{Results}

No complications related to the anaesthesia protocol occurred. In a small number of animals minor bleeding from the fatty tissue around the gland occurred but this was easily managed by applying pressure on the tissue with a dry swab. Given the location, perforation of the abdominal muscle layer or trauma to the penis could occur, but in our cases none of these complications occurred. The most common complication was re-opening of the surgical wound. Eight mice (3.1\%) removed skin sutures within $24 \mathrm{~h}$ post surgery, and the wound was closed again under general anaesthesia. Infection of the surgical wound, with obvious exudate occurred in six mice $(2.3 \%)$ within $24-48$ h post surgery. Antibiotics were administered until infection resolved (typically $72 \mathrm{~h}$ ). Recurrence of an abscess at the surgical site was noted in six mice $(2.3 \%)$.

\section{Discussion}

The incidence of preputial gland inflammation or abscess are influenced by several factors. Mouse strain, age and microbiological flora are considered to be of importance [3-10] but also environmental condition such as group housing have been considered to increase the incidence of the condition [2]. In this case report, the high prevalence of this condition in $\mathrm{C} 3 \mathrm{H} / \mathrm{HeNH}$ sd mice was considered to be due to the high fat diet and the sugar water regimen 


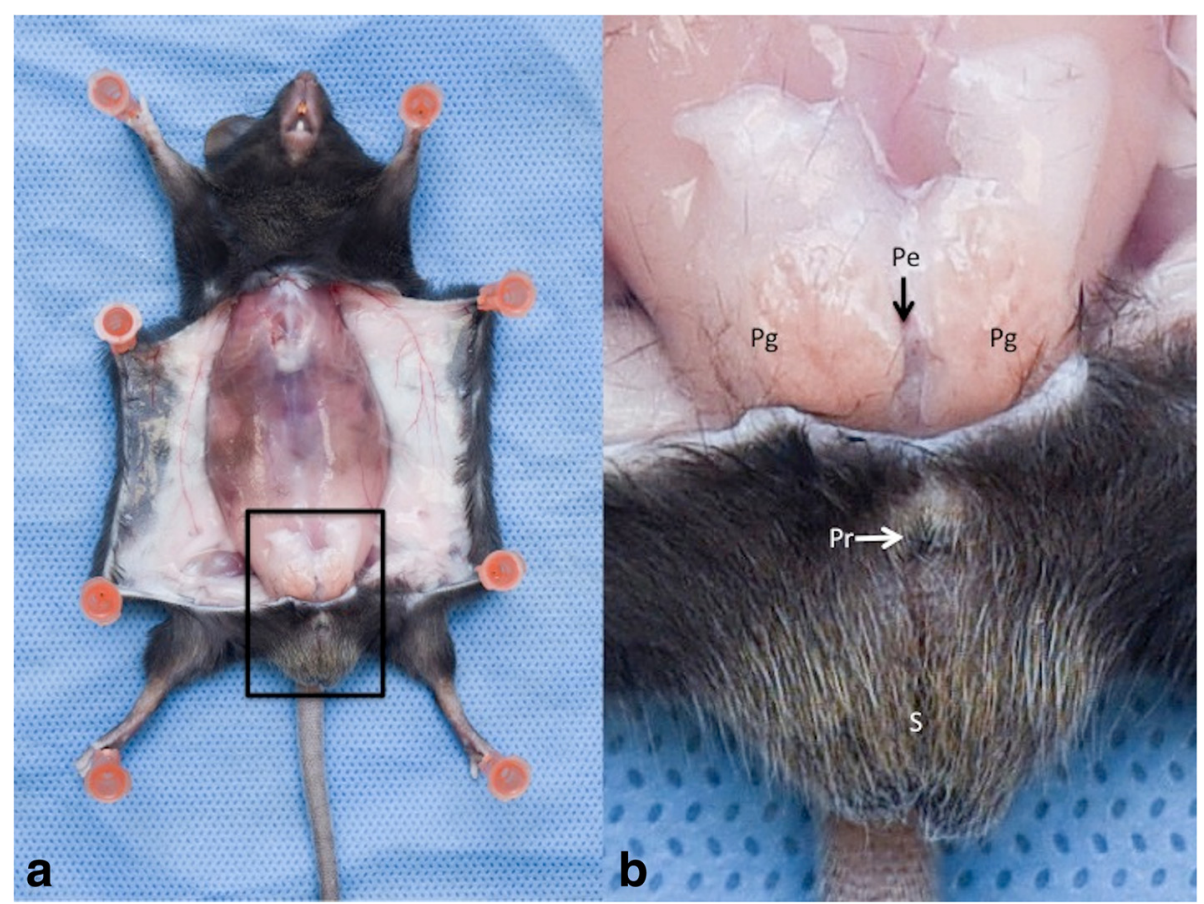

Fig. 1 Anatomic Region of the preputial glands. a General view. The abdominal skin layer has been reclined to expose the muscle layer and the preputial glands region. The black frame represents the area enlarged in the next picture. $\mathbf{b}$ Enlarged view of the preputial glands region.

( $\mathrm{S}=$ Scrotum; $\mathrm{Pr}=$ Prepuce; $\mathrm{Pg}=$ Preputial gland; $\mathrm{Pe}=$ Penis)

used for the main study but no bacterial culture was performed to identify an infectious agent, as this would not have impacted our treatment approach. No histopathology exam was performed to confirm the diagnosis of abscess. This diagnosis was only based on the clinical signs observed and the similar progression of clinical signs in all animals. The treatment suggested in the literature is to lance the abscess and administer antibiotics to the animals $[1,7,11]$. However, in our experience the recurrence rate was high $(95 \%)$ when using this treatment regimen. This might be due to the multilobular structure of the gland preventing complete drainage of the abscess. The recurrence of these abscesses therefore represents a welfare cost for mice, as it may be associated with pain, fever and can lead to systemic amyloidosis [10]. Both a surgical procedure and repeated antibiotic therapy can impact on the welfare of the mice $[12,13]$. The surgical procedure described has the advantages of preventing infection, and resolving established abscesses. It was associated with a low level of complication (in total 20 mice, $7.7 \%$ ). However this procedure is more technically demanding and time consuming than the previously documented treatment regimen. Like other surgical procedures, principles of good aseptic technique should be followed and a nonsterile assistant should be available to prepare the animal for surgery, monitor the anaesthesia and assist the surgeon. The time taken to perform each individual surgery was not recorded but in our experience each surgery required just under $10 \mathrm{~min}$. Isoflurane was considered to be the anaesthetic of choice for this procedure as it provides a fast and smooth induction and recovery and also reliably produces a surgical plane of anaesthesia [14]. The other issue with this procedure, which was not investigated, is the potential impact on reproductive function since these glands play a role during the mating [1]. As a consequence, we only advise surgical removal of the preputial glands if a high incidence of the condition appears associated with a specific study, and when other means of reducing the incidence of the condition have been considered.

\section{Conclusion}

In the study described here, early intervention was successful in preventing intercurrent infection compromising both animal welfare and the outcome of the study.

\section{Methods}

\section{Ethical statement}

Animals were housed in a Home Office (UK authority) accredited facility and in compliance with the Animal Scientific Procedure Act 1986 and the European Directive 2010/63/EU. Newcastle University Animal Welfare and Ethic Review Body and the Home Office approved research protocols. The procedure was performed under the United Kingdom Veterinary Surgeon's Act 1969 with 


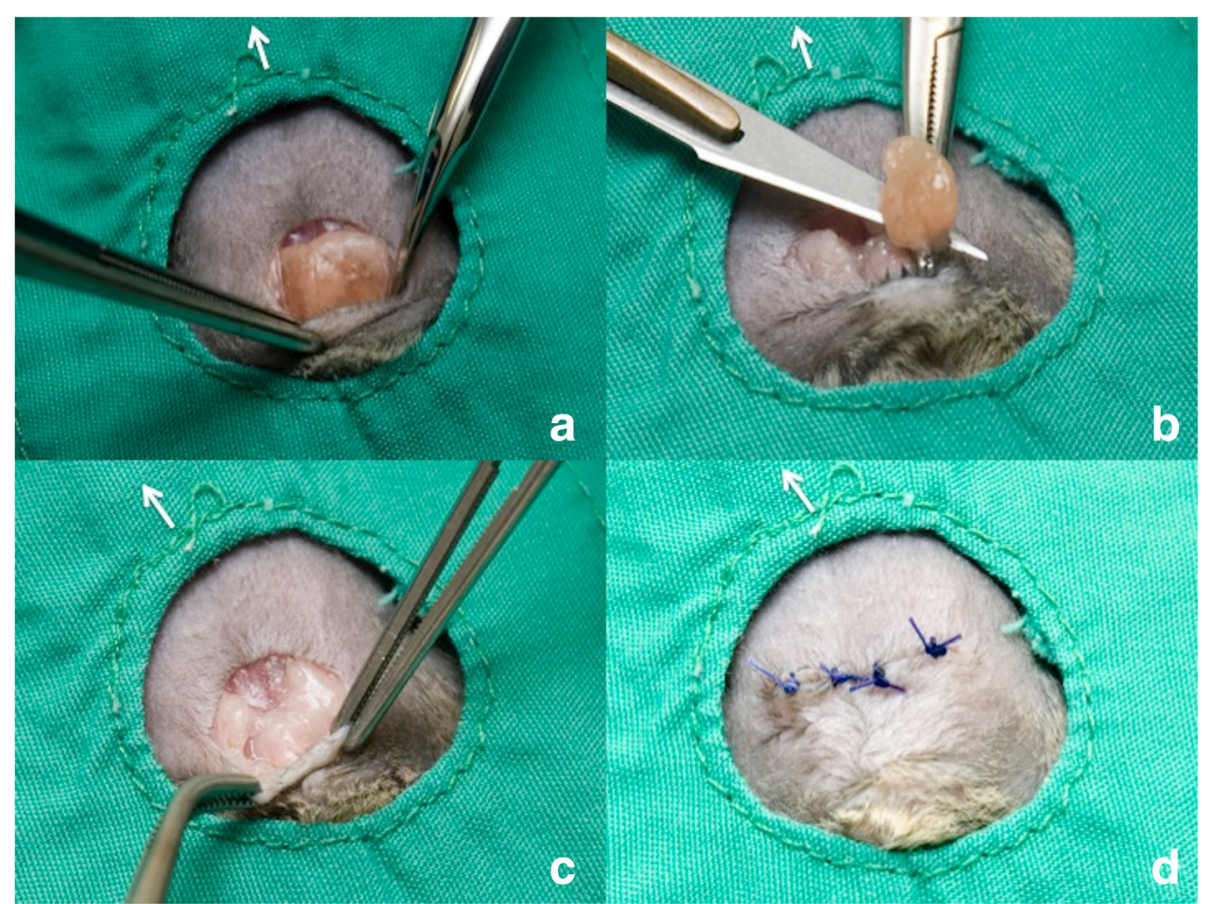

Fig. 2 Ablation surgery of preputial glands. a Preputial glands exposed (b) Gland ablation after haemostat was placed on the duct (c) Surgical site after glands are removed (d) Interrupted pattern suture to close surgical site. The withe arrow indicates the direction of the head

the agreement of the principal investigator and the Home Office.

\section{Animals and husbandry}

This report is based on treatment of 258 male mice $\mathrm{C} 3 \mathrm{H} / \mathrm{HeNH}$ sd (from Harlan Laboratories, UK) involved in a study of the effect of several diets on the formation of liver fibrosis. Animals were aged from 6 to 10 weeks at the start of the study and the first signs of gland inflammation were noted between 18 and 20 weeks of age. In total, 56 mice $(21.7 \%)$ developed at least one gland abscess. The mice were housed in Individually Ventilated Cages $\left(580 \mathrm{~cm}^{2}, 226 \mathrm{~mm} \times 419 \mathrm{~mm} \times\right.$ $147 \mathrm{~mm}$, Arrowmight, UK), with 20 air cycles per hour. The day-night cycle was $12-12 \mathrm{~h}$ and the temperature was maintained at $22+/-2{ }^{\circ} \mathrm{C}$. During the study, an increasing number of mice presented with inflammation of their preputial glands. Because of the large number of affected animals, and because medical management of similar cases had proved unsuccessful, surgical removal of the gland was proposed.

\section{Surgical procedure and perioperative cares}

Anaesthesia was induced with $5 \%$ and maintained with $2.5 \%$ of isoflurane (IsoFlo $100 \%$ w/w Inhalation Vapour, Abbott Laboratories, Maidenhead, UK), in 100 \% oxygen. Anaesthesia was maintained for no more than $10 \mathrm{~min}$. Body temperature was maintained with a heat pad set at
$38{ }^{\circ} \mathrm{C}$ (Homeothermic Blanket system, Harvard Apparatus, Cambridge, UK). Meloxicam (5 mg/g s/c) (Metacam, Boehringer Ingelheim Limited, Bracknell, UK) was administered $10 \mathrm{~min}$ prior to surgery for pain relief and enrofloxacin $(10 \mathrm{mg} / \mathrm{kg} \mathrm{s} / \mathrm{c})$ (Baytril $2.5 \%$ solution for injection, Bayer plc, Newbury, UK) as prophylactic antibiotic therapy. The preputial region was prepared for aseptic surgery (http:// www.procedureswithcare.org.uk/aseptic-technique-in-rode nt-surgery/). A $15 \mathrm{~mm}$ transverse skin incision was made cranial to the prepuce using a number 11 scalpel blade. The subcutaneous tissues were gently dissected forward to the prepuce with Metzenbaum scissors and Debakey forceps, without touching the penis. The healthy gland appeared as a flattened circular structure with a cream to light brown colouration (Fig. 1). In contrast the infected gland appeared larger and thin walled with a yellow-red colouration [15]. When a gland was infected, pus was often visible in one lobe of the gland or disseminated throughout. Some glands were embedded in fatty tissue, necessitating its isolation by gentle manipulation with a sterile cotton bud or a swap. Each gland was removed using a hemostat is placed on the ventral side of its duct, followed by cutting proximally with a scalpel blade 11 . In animals with abscessation of the gland, adhesions with the skin necessitated very careful dissection before removal. If the gland ruptured during this dissection the surgical wound was thoroughly flushed with sterile saline and an additional dose of enrofloxacin administered at $24 \mathrm{~h}$ post-surgery. The skin was 
closed with polyglactin 910, 4/0 suture (Coated VicrylEthicon, Johnson\&Johnson international, Diegrem, Belgium) with an interrupted pattern and skin glue (Indermil xfine, Henkel, Dublin, Ireland) to reinforce the closure (Fig. 2).

\section{Competing interests}

None of the authors of this paper has a financial or personal relationship with other people or organizations that could inappropriately influence or bias the content of the paper. The authors declare that they have no competing interests.

\section{Authors' contributions}

$H B, A T$ and PF developed the surgical procedure and collected the data. $H B$ and $A T$ performed the surgery and $Y E$ and RD provided anaesthesia and perioperative cares support. The final version of the manuscript was read and approved by all authors of this study.

\section{Author details}

${ }^{1}$ Comparative Biology Centre, Newcastle University, Framlington Place, Newcastle Upon Tyne NE2 4HH, UK. ${ }^{2}$ School of Veterinary Medicine and Science, Nottingham University, Nottingham, UK. ${ }^{3}$ Institute of Neurosciences, Newcastle University, Newcastle Upon Tyne, UK.

Received: 22 May 2015 Accepted: 14 January 2016

Published online: 19 January 2016

\section{References}

1. Laber-Laird K, Swindle M, Flecknell PA. Handbook of Rodent and Rabbit Medicine. Oxford: Elsevier Science; 1996.

2. Tanabe M, Kimura T. Aggression and preputial gland of male mice affected by the presence of other males. J Ethol. 1995;13:63-8.

3. Ward JM, Goodman DG, Squire RA, Chu KC, Linhart MS. Neoplastic and nonneoplastic lesions in aging (C57BL/6N x C3H/HeN)F1 (B6C3F1) mice. J Natl Cancer Inst. 1979;63:849-54.

4. Holtfreter S, Radcliff FJ, Grumann D, Read H, Johnson S, Monecke S, et al. Characterization of a mouse-adapted staphylococcus aureus strain. PLoS One. 2013;8:e71142.

5. Rowlatt C, Chesterman FC, Sheriff MU. Lifespan, age changes and tumour incidence in an ageing C57BL mouse colony. Lab Anim. 1976;10:419-42.

6. Hong CC, Ediger RD. Perputial gland abscess in mice. Lab Anim Sci. 1978:28:153-6.

7. Fox JG, Anderson LC, Loew FM, Quimby FW. Laboratory Animal Medicine. 2nd edition. San Diego: Elsevier Science; 2002.

8. Marchlewska-Koj A, Ponchron E, Sliwowska A. Salivary glands and preputia glands of males as source of estrus-stimulating pheromone in female mice. J Chem Ecol. 1990;16:2817-22.

9. Needham JR, Cooper JE. Bulbourethral gland infections in mice associated with Staphylococcus aureus. Lab Anim. 1976;10:311-5.

10. Radaelli E, Manarolla G, Pisoni G, Balloi A, Aresu L, Sparaciari P, et al. Suppurative adenitis of preputial glands associated with corynebacterium mastitidis infection in mice. J Am Assoc Lab Anim Sci. 2010;49:69-74.

11. Harkness JE, Turner PV, VandeWoude S, Wheler CL. Harkness and Wagner's Biology and Medicine of Rabbits and Rodents. 5th edition. Ames, IA: Wiley-Blackwell; 2013.

12. Miller AL, Wright-Williams SL, Flecknell PA, Roughan JV. A comparison of abdominal and scrotal approach methods of vasectomy and the influence of analgesic treatment in laboratory mice. Lab Anim. 2012;46:304-10.

13. Davis JN, Courtney CL, Superak H, Taylor DK. Behavioral, clinical and pathological effects of multiple daily intraperitoneal injections on female mice. Lab Anim (NY). 2014:43:131-9.

14. Flecknell P. Laboratory Animal Anaesthesia. 4th edition. Oxford: Elsevier Science; 2015.

15. Donnelly TM, Walberg J. Enlarged mouse preputial glands. Lab Anim (NY). 2011:40:69-71.

\section{Submit your next manuscript to BioMed Central and we will help you at every step:}

- We accept pre-submission inquiries

- Our selector tool helps you to find the most relevant journal

- We provide round the clock customer support

- Convenient online submission

- Thorough peer review

- Inclusion in PubMed and all major indexing services

- Maximum visibility for your research

Submit your manuscript at www.biomedcentral.com/submit 